\title{
Selectivity of Fatty Acid Release From Macrophages Following Various Stimuli
}

\author{
MARK D. WIEDERHOLD, WEI HSUEH AND M. MITSUO YOKOYAMA
}

Department of Pathology, University of Illinois at the Medical Center, Chicago, Illinois 60612, Department of Pathology, Childrens Memorial Hospital, Northwestern University Medical School, Chicago, Illinois 60614, U.S. A. and Department of Imminology, Kurume University School of Medicine, Kurume, 830 Japan

Received for publication January 11, 1985

\begin{abstract}
Summary: Cultured rabbit alveolar macrophages release various fatty acids, prostaglandins and other arachidonic acid metabolites upon stimulation. The selectivity of fatty acid release depends on the stimulus used. Zymosan, a phagocytic inflammatory stimulus, causes a fourfold increase in prostaglandin release, and a threefold specific release of arachidonic acid. Phorbol myristate acetate, causes a fourfold increase in prostaglandin release, and a non-specific release of long-chain fatty acids. Bacterial lipopolysaccharide leads to nonspecific release of the long-chain fatty acids, but a minor increase in prostaglandin production. These data suggest that fatty acid release during phagocytosis is a specific cellular response rather than non-specific lipid hydrolysis. The potential significance of fatty acid release in macrophage function was discussed.
\end{abstract}

Key words: macrophage — fatty acid — prostaglandin — arachidonic acid mitogen

\section{Introduction}

The concept of the macrophage as an effctor cell in immunologic host defense is gaining wide acceptance. A number of bioactive substances secreted or released by macrophages have increasingly been reported (Ogmundsdottir and Weir, 1980; Ferluga et al. 1978; Gordon et al. 1977; Wahl et al. 1974). Of particular interest is the production of prostaglandins (PG) and other arachidonic acid metabolites by macrophages and the elicitation of these substances by inflammatory agents (Humes et al. 1977). The significance of prostaglandin release from macrophages is unclear; however, evidence which suggests control of target cell function, especially lymphocyte function, has invoked much discussion (Mihas et al. 1975; Smith et al. 1971; Goodwin et al. 1977; Goodwin et al. 1977).

Since prostaglandins are not stored but are synthesized de novo by the cell, the availability of arachidonic acid becomes important in the production of prostaglandins (Piper and Vane, 1971). Phospholipase $\mathrm{A}_{2}$ which cleaves the number two position in phospholipids is important in providing the bulk of arachidonic acid (AA) for PG production (Vogt, 1978).

Previous reports showed most arachidonic acid that was released by cells was converted to PGs, since little free AA could be detected in the medium (Scott et al. 1980). This lack of free AA in the medium could be due to efficient re-incorporation of AA into phospholipids. We have previ- 
ously described a method using fatty acid free bovine serum albumin (BSA) in the culture medium to "trap" the released AA, and determined that the amount of AA released was three times the amount that was converted to PG during stimulation (Hsueh et al. 1979).

Since phagocytosis is a complex process which involves formation of phagosome, vesicles, fusion of phagosomes with lysosomes and subsequent recycling of the cell membrane, it is important to address ourselves to the following questions: a) Is the release of AA a result of selective deacylation of lipids, or a non-specific release of all fatty acids due to internalization and recycling of the cell membrane which takes place during phagocytosis?, and b) Do other non-phagocytic stimuli such as phorbol myristate acetate (PMA) or endotoxin (LPS) have the same effect on deacylation of phospholipids as zymosan phagocytosis? In the present study, we demonstrate a selective release of arachidonic acid during zymosan phagocytosis, and a non-selective release of long chain fatty acids by macrophages during PMA and endotoxin stimulation.

\section{Materials and Methods}

\section{Materials}

Zymosan, phorbol myristate acetate, phospholipid standards, bacterial endotoxin and phospholipase $\mathrm{A}_{2}$ (from porcine pancreas, 600 units $/ \mathrm{mg}$ protein) were obtained from Sigma Chemical Co., St. Louis, MO.

${ }^{14} \mathrm{C}$-arachidonic acid was purchased from New England Nuclear, Boston, MA, boron trifluoride-methanol, and fatty acid standards were obtained from Supelco, Inc., Bellefonte, PA. Fatty acid free bovine serum albumin (BSA) (Calbiochem, La Jolla, -CA), was prepared by extracting twice with ether.

12-HETE standards were prepared from washed human platelets as described by
Goetzl et al. (1977).

\section{Rabbit alveolar macrophage culture}

Macrophages from normal adult male New Zealand rabbits were obtained via lung lavage following transsection of the abdominal aorta. The cells were lavaged in ethylenediamine tetraacetate $10^{-3} \mathrm{M}$ buffered saline containing $100 \mathrm{U} / \mathrm{ml}$ penicillin and $100 \mu \mathrm{g} / \mathrm{ml}$ streptomycin. The cells were washed three times in serum free Dulbecco's Modified Eagle Medium (DMEM), (Gibco, Grand Island, NY), counted in a haematocytometer and stained for viability with trypan blue dye. Viability was routinely found to be higher than $95 \%$. The cells were plated in DMEM with $100 \mathrm{U} / \mathrm{ml}$ penicillin and $100 \mu \mathrm{g} / \mathrm{ml}$ and streptomycin at a concentration of $5.5 \times 10^{6}$ cells $/ \mathrm{ml}$ into $1 \mathrm{ml}$ culture plates. The lavaged cells consisted of approximately $95 \%$ alveolar macrophages, and $5 \%$ lymphocytes, red blood cells and an occasional neutrophil or bronchial epithelial cell. The cells were cultured overnight at $37^{\circ} \mathrm{C}$, washed once with DMEM and unattached cells were discharded. Fresh serum free DMEM was added containing $2.5 \mathrm{mg} / \mathrm{ml}$ fatty acid free BSA. BSA was used to trap fatty acids after their release to prevent reacylation by the macrophages. Fetal calf serum was not used for fear of lipid contaminants. Duplicate cultures were stimulated with $1 \times 10^{-6} \mathrm{M}$ PMA, $2 \mu \mathrm{g} / \mathrm{ml}$ of bacterial endotoxin from Shigella flexneri or $1 \mathrm{mg} / \mathrm{ml}$ zymosan (Sigma Chemical Co., St. Louis, MO) for 24 hours. These dosages were used in order to get the maximal amount of stimulation without causing significant cell death.

\section{Determination of fatty acids}

After 24 hours, the culture medium was collected and centrifuged for 5 minutes at $2000 \mathrm{rpm}$ to remove all cells and/or debris. Twenty-four hours was chosen in order to allow the release of an amount of lipid which could be accurately quantitated by 
gas chromatography. The cells were either fixed in ethanol and stained with hematoxylin and eosin, Wrights stain or PAS for morphology, or the cells were stained with trypan blue for viability. The cell-free culture supernatant, from each plate was acidified with $2 \mathrm{~N}$ formic acid, to $\mathrm{pH} 3$ to 3.5 , and then extracted three times with ethyl acetate. Internal standards $(0.4 \mathrm{mg}$ $/ \mathrm{ml}$ of methylheptanonate) were added and the samples stored at $-20^{\circ} \mathrm{C}$ under an atomosphere of nitorgen. Fatty acid methyl esters were made according to the following procedure. Extracted fatty acids were derid down under a stream of nitrogen in a $40^{\circ} \mathrm{C}$ water bath, dissolved in $1 \mathrm{ml}$ of benzene, and transferred to Supelco ${ }^{\circledR}$ reaction vials. Borontraifluoride-methanol $(0.2 \mathrm{ml})$ was added and the reaction vials were capped and heated in a boiling water bath for 3 minutes. After cooling, the reaction was stopped with the addition of $1.0 \mathrm{ml}$ of distilled water. The benzene was removed after centrifugation and dried down under a stream of nitrogen and the methyl esteres of fatty acids were dissolved in hexane or disthyl ether. A Fisher model 4800 gas chromatograph with a $2 \mathrm{~mm} \mathrm{ID,} 6 \mathrm{ft}$. column packed with $10 \%$ DEGS on $80 / 100$ Supelcoport.
The levels of fatty acid present in the culture media (DMEM) and in the "fatty acid free" BSA examined and were found to be less than $10 \%$ of the fatty acid release of control (unstimulated cells). The level of fatty acid release during the attachment of macrophages was also examined. During a 2 hour attachment phase, the level of fatty acids released was not significant. The level of fatty acids present in the stimulating agents, i. e., zymosan, PMA and LPS, were also determined following extraction with ethyl acetate, and these values were also not significant.

The results of the fatty acid hydrolysis experiments are shown in Table 1 . The levels of fatty acid in the cell lipids calculated by total cell saponification, shown that arachidonic acid is present in levels that are 2 fold greater than stearic, oleic and linoleic acids. Table 1 also shows the levels of fatty acids esterified at position number 2 in phospholipids. The data indicate that arachidonic acid is the most abundant fatty acid at position number 2 in phospholipids. Arachidonic acid is present in a greater than 3 fold level than stearic, a greater than 8 fold level than oleic, and a greater than 2 fold level than linoleic acids. The release of fatty acids

TABLE 1

Fatty acid profile of normal macrophages

\begin{tabular}{c|cccc}
\hline \multirow{2}{*}{ Treatment } & \multicolumn{4}{|c}{ Fatty acid in $\mu \mathrm{g} / 5 \times 10^{6}$ cells } \\
\cline { 2 - 5 } & $18: 0$ & $18: 1$ & $18: 2$ & $20: 4$ \\
\hline $\begin{array}{c}\text { (a) Total cell saponification } \\
(\mathrm{n}=10)\end{array}$ & $0.442 \pm 0.01$ & $0.526 \pm 0.05$ & $0.660 \pm 0.03$ & $1.154 \pm 0.08$ \\
\hline $\begin{array}{c}\text { (b) Phospholipase } \mathrm{A}_{2} \text { treatment } \\
(\mathrm{n}=3)\end{array}$ & $0.105 \pm 0.03$ & $0.045 \pm 0.005$ & $0.158 \pm 0.05$ & $0.408 \pm 0.04$ \\
\hline
\end{tabular}

(a) Total fatty acid content of normal macrophages for 18:0 (stearic acid); 18:1 (oleic acid); 18:2 (linoleic acid), and 20:4 (arachidonic acid). The unstimulated macrophages were treated with methanolic $\mathrm{KOH}$ overnight. The fatty acids were extracted and analyzed by gas chomatography (See Method). $\mu$ g of lipid were calculated via triangulation comparisons with fatty acid methyl ester standards.

(b) Normal macrophages were treated with $0.5 \mathrm{mg}$ phospholipase for 8 hours. The fatty acids released were extracted, methylated, and analyzed with gas chromatography. 
was also compared to the release of prostaglandins and 12-HFTE under similar conditions, as shown in Table 2. The level of prostaglandin release due to zymosan or PMA treatment ranged from 2 to 3 fold greater than the control (unstimulated). The levels of PG release due to LPS however were only mildly elevated compared with control, and this change was not significant. While indomethacin had been shown to block synthesis and release of PG, it increases the amount of arachidonic acid released from phopholipids (data not shown). Zymosan showed a 3 fole and PMA a 4 fold increase in the levels of 12-HETE as compared to the control. LPS only revealed a mild was used to detect fatty acid methyl esters. A Hamilton syringe was used to inject $3 \lambda$ of sample into the instrument which had a column temperature of $190{ }^{\circ} \mathrm{C}$, a nitrogen flow of 20 $\mathrm{ml} / \mathrm{min}$ and an FID detector at $250^{\circ} \mathrm{C}$. The column was repacked after 40-50 samples had been injected. Peak areas were calculated by triangulation and areas were corrected in relation to the internal standard.

\section{Total Lipid Hydrolysis}

In order to exmaine the relationship between fatty acid release, and total fatty acid content of alveolar macrophage lipids, total cell saponification was arried out. Approximately $5.5 \times 10^{6}$ cells each were placed into 10 siliconized tubes containing $1 \mathrm{ml}$ of $40 \%$ potassium hydroxide in methanol. The tubes were heated at $37^{\circ} \mathrm{C}$ for 8 hours and the methanol removed by evaporation with $\mathrm{N}_{2}$. The $\mathrm{pH}$ was adjusted to 3 to 3.5 with concentrated hydrochloric acid, and fatty acids extracted with ethyl acetate. Fatty acid methyl esters were prepared and determined by gas chromatography as described above.

Phospholipase $\mathrm{A}_{2}$ (Sigma Chemical Co., St. Louis, MO) was used to determine the fatty acid profile at position number 2 in phospholipids, approximately $5.5 \times 10^{6}$ cells were treated with $0.5 \mathrm{mg}$ of phospholipase $\mathrm{A}_{2}$ for 12 hours at $37^{\circ} \mathrm{C}$ in DMEM at a pH of 7.5 Following hydrolysis the supernatant was centrifuged and extracted as described above.

\section{Measurement of Prostaglandins}

${ }^{14} \mathrm{C}$-arachidonic acid (specific activity $55 \mathrm{mCi} \mathrm{mmol}{ }^{-1}$ ) was added to duplicate cultures of $5.5 \times 10^{6} \mathrm{cells} / \mathrm{ml}$ as the sodium salt at a concentration of $1 \times 10^{6}$ counts/ min. $\mathrm{ml}^{-1}$. The radioactive arachidonic acid was allowed to incorporate into cell lipids for 16 hours. Following incorporation, the

TABLE 2

Release of arachidonic acid metabolites

\begin{tabular}{lcccc}
\hline & $\begin{array}{c}\text { Control } \\
(\mathrm{cpm})\end{array}$ & $\begin{array}{c}\text { Zymosan } \\
(\mathrm{cpm})\end{array}$ & $\begin{array}{c}\text { PMA } \\
(\mathrm{cpm})\end{array}$ & $\begin{array}{c}\text { LPS } \\
(\mathrm{cpm})\end{array}$ \\
\hline 6-keto PGF $1 \alpha$ & $126.8 \pm 18.6$ & $289.2 \pm 109.9$ & $390.7 \pm 104.7$ & $138.4 \pm 18.8$ \\
$\mathrm{PGF}_{2} \alpha$ & $103.5 \pm 8.9$ & $279.6 \pm 81.0$ & $386.8 \pm 82.4$ & $117.1 \pm 19.5$ \\
$\mathrm{PGE}_{2}$ & $139.3 \pm 14.8$ & $453.8 \pm 137.1$ & $588.5 \pm 193.0$ & $148.8 \pm 7.0$ \\
$\mathrm{PGD}_{2}$ & $83.3 \pm 6.4$ & $232.6 \pm 69.2$ & $349.8 \pm 91.4$ & $88.6 \pm 13.5$ \\
12 -HETE & $82.2 \pm 4.2$ & $314.5 \pm 18.7$ & $449.4 \pm 222.1$ & $89.1 \pm 9.0$ \\
\hline
\end{tabular}

The macrophages were stimulated with zymosan, PMA, or LPS for 24 hours. The AA metabolites were extracted, plated and developed in solvent system "A-9" (38). Zones corresponding to various PG standards were scraped and counted $(\mathrm{n}=4$, Mean \pm S.E.M. $)$. 
cells were washed twice to remove any unlabeled arachidonic acid. Stimulation with zymosan, PMA and LPS was performed as described above. The prostaglandins were extracted by the method described above for fatty acids. The samples were dried down under a stream of nitrogen and applied to silica gel $\mathrm{G}$ plates. The solvent system used was the organic phase from ethyl acetate: water: iso-octane: acetic acid; $110: 100: 50: 20)$ Zones corresponding to various prostaglandin standards and 12-hydroxyeicosa-5, 8, 10. 14 -tetraeonic acid (12-HETE) scraped and counted in a liquid scintillation counter after identification with iodine vapor. ${ }^{14} \mathrm{C}$ arachidonic acid labeled macrophages were scraped from culture plates and transferred to siliconized tubes. Lipids were extracted with chloroform: methanol; $2: 1$, and the percentage of incorporation into phospholipids was determined. The chloroform: methanol lipid extract was washed twice with $3 \mathrm{ml}$ of distilled water followed by centrifugation and discarding of the aqueous layer, dried down and plated on silica gel $\mathrm{G}$ plates. The phospholipids were developed using the solvent system chloroform: methanol: ammonium hydroxide;
$65: 35: 5$. Zones corresponding to phospholipid standrds were scraped and counted in a liquid scintillation counter. increase in the release of 12-HETE. Table 3 shows the distribution of radioactive arachidonic acid in cell lipids. The majority $(50 \%)$ of AA was incorporated into phosphatidylethanolamine (PE), approximately $30 \%$ was incorporated into phosphatidylcholine (PC), and 5-10\% into neutral lipids. Less than $6 \%$ was incorporated into phosphatidylserine (PS) and phosphatidylinositol (PI). The remainder of the label was found in an undefined band $\mathrm{X}$ which migrated below neutral lipids (79\%), and on unscraped areas of the plate and material left on the silica gel not extracted by the methanol wash. The levels of radioactive label did not change in significant amounts, except for a minor preference for the PS/PI fraction following LPS stimulation. Very low levels of free fatty acid were present.

\section{Results}

The results of the experiment measuring fatty acid release upon stimulation are shown in Figure 1. Fig. 1a shown that

TABLE 3

Incorporation of ${ }^{14} \mathrm{C}$-arachidonic acid into cell lipids

\begin{tabular}{|c|c|c|c|c|c|c|c|c|}
\hline & \multicolumn{2}{|c|}{ Control } & \multicolumn{2}{|c|}{ Zymosan } & \multicolumn{2}{|c|}{ PMA } & \multicolumn{2}{|l|}{ LPS } \\
\hline & $\mathrm{cpm}$ & $\%$ & $\mathrm{cpm}$ & $\%$ & $\mathrm{cpm}$ & $\%$ & $\mathrm{cpm}$ & $\%$ \\
\hline Neutral lipid & $3080 \pm 903$ & 4.5 & $4058 \pm 205$ & 10.5 & $5248 \pm 382$ & 5.1 & $2276 \pm 168$ & 4.7 \\
\hline Fatty acid & $666 \pm 170$ & 0.7 & $1027 \pm 63$ & 1.2 & $1217 \pm \quad 81$ & 1.4 & $187 \pm \quad 42$ & 0.9 \\
\hline $\mathrm{PE}$ & $37943 \pm 1075$ & 49.6 & $43044 \pm 1458$ & 46.7 & $34795 \pm 2123$ & 46.4 & $31970 \pm 1719$ & 51.3 \\
\hline $\mathrm{PC}$ & $25335 \pm 757$ & 30.4 & $30165 \pm 1385$ & 30.1 & $28349 \pm 1915$ & 30.4 & $20726 \pm 1128$ & 30.6 \\
\hline $\mathrm{PS} / \mathrm{PI}$ & $6033 \pm 320$ & 5.3 & $5237 \pm 362$ & 5.0 & $5150 \pm 391$ & 4.9 & $1808 \pm 94$ & 3.2 \\
\hline $\begin{array}{l}\text { Total CPM } \\
5 \times 10^{6} \text { cells }\end{array}$ & $80846 \pm 1452$ & 100 & $88703 \pm 1865$ & 100 & $89677 \pm 1954$ & 100 & $86676 \pm 1732$ & 100 \\
\hline
\end{tabular}

Macrophages were labelled with ${ }^{14} \mathrm{C}$-arachidonic acid for 16 hours, washed, and were stimulated with various agents. The cell lipids were extracted with chloroform: methanol (2:1), plated and developed in chloroform: methanol: $\mathrm{NH}_{4} \mathrm{OH}(65: 35: 5)$. Zones corresponding to various phospholipid standard were scraped, counted and expressed as $\%$ of total $\mathrm{cpm}$ applied to plates $(\mathrm{n}=4$, mean \pm S. E. M. $)$. 

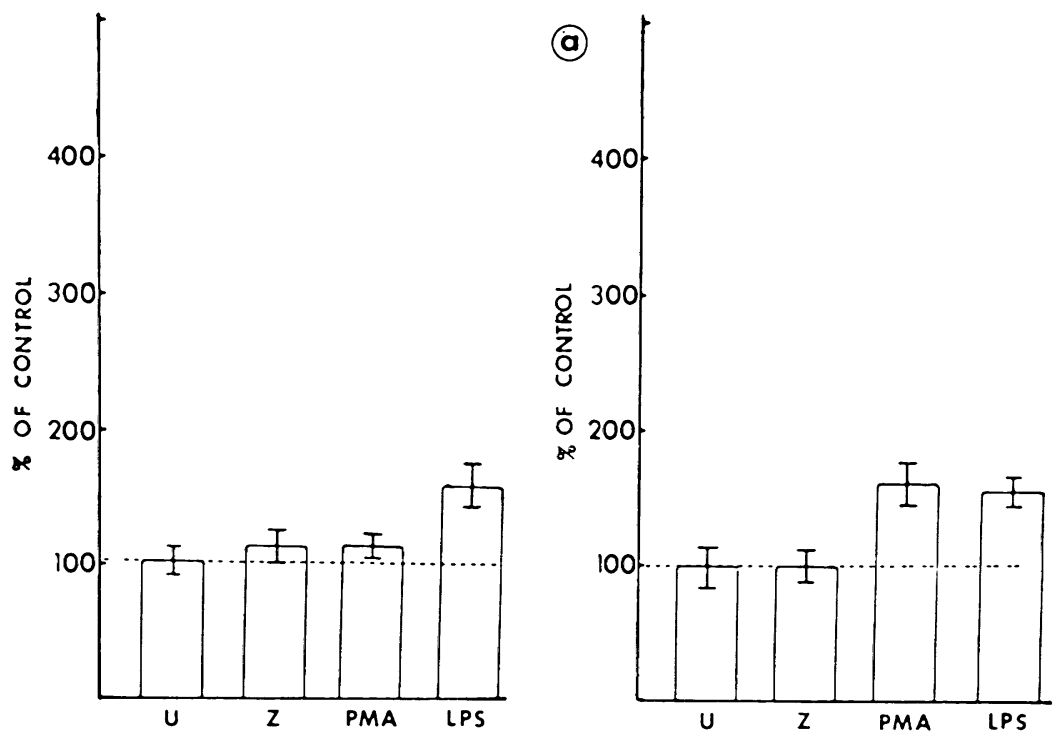

(b)
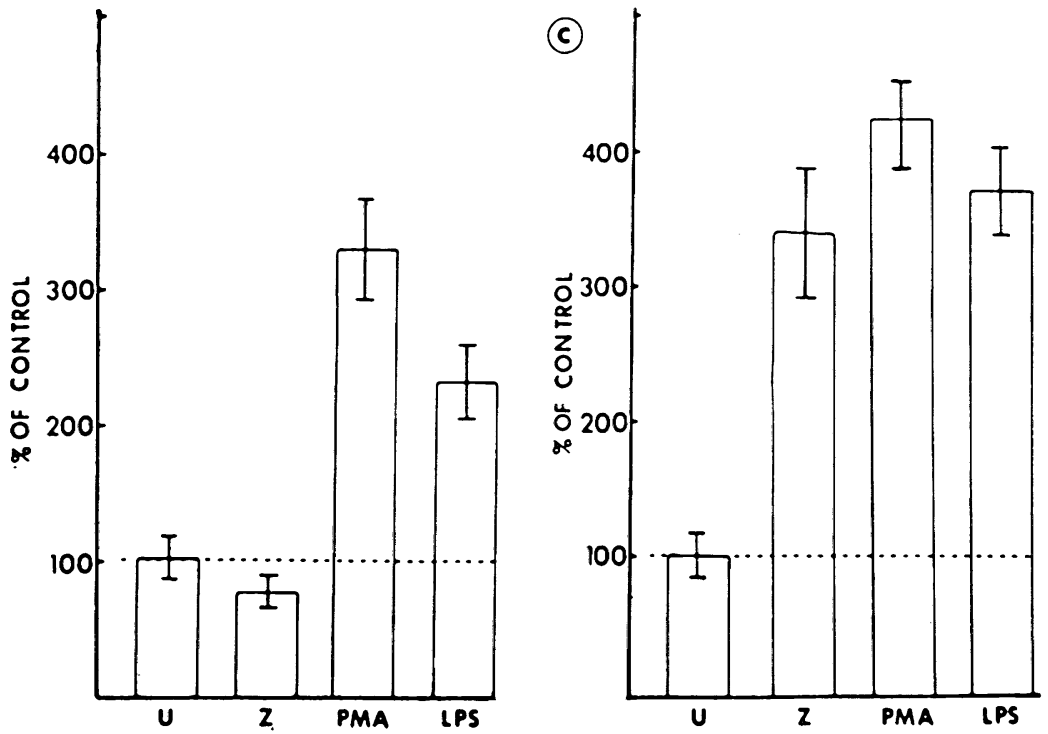

Fig. 1. Release of fatty acids following various stimuli. Alveolar macrophages were stimulated for 24 hours with zymosan ( $Z$ ), phorbol myristate acetate (PMA), and bacterial lipopolysaccharide (LPS). Culture media were extracted, methylated and analyzed by GC (See Methods). The fatty acids studied were (a) stearic acid, (b) oleic acid, (c) linoleic acid, (d) arachidonic acid. Values represent an average of five experiments and are expressed as a percentage of the unstimulated control (Mean \pm S. E. M.). 
stearic acid was not released in significant amounts following stimulation, except for bacteriall lipopolysaccharide (LPS) treatment which showed a $50 \%$ increase. Fig. $1 \mathrm{~b}$ shows a significant release of oleic acid by both PMA and LPS, which was on the order of a $50 \%$ increase for both. Fig. 1c shows a 3 fold increase in the release of linoleic acid for PMA and a greater than 2 fold increase due to LPS. Fig. 1d showed that arachidonic acid was released in significant amounts by all stimuli used. Zymosan resulted in a greater than 3 fold increase, PMA a 4 fold increase and LPS a greater than 3 fold increse in the release of aracihidonic acid. If Fig. $1 \mathrm{a}-\mathrm{d}$ are examined collectively, it appears that the diand tetra-unsaturated fatty acids, i.e., arachidonic and linoleic acids, are released in greater amounts than stearic and oleic acids. Observing the type of stimulus used also provided some interesting results. Zymosan appeared to selectively cause an increase in the release of arachidonic acid only, while PMA seemed to cause an increase in the release of unsaturated fatty acids that were examined. LPS however appeared not to be selective, and caused an increase in the release of all fatty acids shown in Fig. 1. Linoleic acid was not released in noticeable amounts by the cells following any stimulation. This reflects the fact that the level of linoleic acid is very low in the cell. The amount of fatty acid equal to $100 \%$ was quantitated by comparison with a standard curve prepared from known amounts of standard. The values are as follows: a) stearic acid. 0.04 $\mu \mathrm{g}, \mathrm{b})$ oleic acid $0.05 \mu \mathrm{g}, \mathrm{c})$ linoleic acid $0.04 \mu \mathrm{g}$ and d) arachidonic acid $0.09 \mu \mathrm{g}$.

\section{Discussion}

Macrophage have been shown to release prostaglandins in response to various stimuli (Bonney et al. 1979; Humes et al. 1978; Passwell et al. 1980; Passwell et al.
1979). Whether macrophages also release fatty acids, however, have been a controversial subject. Some investigators (Scott et al. 1980) reported little or no free long chain fatty acids released from macrophages. This was most likely due to rapid reincorporation of the fatty acid into cells. By adding BSA in the medium to "trap" the free fatty acids, we are able to detect true fatty acid release by macrophages following stimulation.

Three types of stimulation were used in our experiments in an attempt to activate the membrane in different ways. Zymosan, an inflammatory phagocytic stimulus, was used to activate the macrophages. Phagocytosis of these particles led to a 2 fold selective increase in the release of arachidonic acid. This result suggests that the fatty acid release during zymosan phag ocytosis represents a specific cellular response rather than non-specific fatty acid "escape" during phagosome formation, phagosome-lysosome fusion and membrane recycling. The physiological significance of the AA release is obvious: arachidonic acid is the precursor of prostaglandins, which are important mediators of the inflammatory process. Our present results show that this increase of fatty acid release is in fact accompanied by a concommitant biosynthesis of prolstaglandins. The selectivity of fatty acid release has been reported in other cell systems and perfused organs (Hsueh et al. 1977; Bills et al. 1977; Hong and Levine, 1976). These studies were performed by prelabelling the cells with radioactive fatty acids. An argument can be made that this does not represent an accurate description of the release of fatty acids. One possible problem is that only the rapidly metabolized pool of lipids are labeled, and that this may not be the sole contributor of fatty acid release following stimulation. In this study we used gas chromatography in the determination of fatty acid release, to overcome this limitation. 
Prosraglandin biosynthesis is not always preceded by a specific liberation of arachidonic acid, which is shown by the results found with PMA. Along with an increased biosynthesis of prostaglandins, a 2 to 3 fold increase in the release of oleic, linoleic and arachidonic acids are observed. PMA is a membrane perturbant, which has also been shown to affect $10 \mathrm{~nm}$ filaments in macrophages (Croop et al. 1980; Hsueh et al. 1979) and induce enzyme activity in cell (Hsueh et al. 1981). The non-specific release of various long-chain fatty acids might represent a non-specific effect on lipid hydrolysis caused by membrane perturbation.

The liberation of fatty acids does not always lead to prostaglandin biosynthesis of the same magnitude. The experiments with LPS show an increase in the release of fatty acids but only a mild elevation of prostaglandin production. LPS in a high dosage is toxic to cells, and the low dose used in our experiments $(2 \mu \mathrm{g} / \mathrm{ml})$ led to a nonspecific release of fatty acids as compared to a specific release of arachidonic acid with zymosan.

The selectivity of fatty acid release may relate to a heterogenesity of lipases which are activated by different stimuli. A number of phospholipase have been isolated from mammalian cells (De Haas et al. 1968), and the possibility that a specific phospholipase existing for arachidonic acid containig phospholipids should be considered. Hauser and Guyer (1979) have shown clustering of fatty acids in lipid bilayers. If similar fatty acids aggregated into specific regions, analogous to "like dissolves like", the possibility of phospholipase activity directed to this region may also be involved.

Fig. 1 also indicates a preferential release of unsaturated fatty acids by the activated cell. For arachidonic acid, the cyclooxygenase and lipoxygenase pathways await its release. Hubbard et al. (1980) showed the formation of hydroxy fatty acids from linoleic acid in $\mathrm{VX} 2$ carcinoma. It would be interesting to see if a similar pathway exists in macrophages. The unsaturated fatty acids are important precursors in other metabolic pathways (Mahler, 1964). This may be one explanation for their predominance in the number 2 position in phospholipids. While phospholipase $\mathrm{A}_{2}$ liberates AA from phospholipids, Bell et al have shown phospholipase $\mathrm{C}$ to be important in the diglyceride lipase pathway in platelets (Bell et al. 1979). Phospholipids however are not the only source of unsaturated fatty acids, since Schremmer et al (1979) suggest plasmalogens are an important source of arachidonic acid for prostaglandin production. In addition to being imprtant precursors, fatty acids may play another role for the macrophage. Free fatty acids have been shown to incorporate rapidly into lipid bilayers (Meade and Mertin, 1978). The "fluidity" of the cell membrane is to some extent influenced by the type of fatty acid chains esterified to polar head groups (Hatten et al. 1978). Thus an increase in the level of unsaturated fatty acids into the cell membrane, via incorporation from the outside media, may be one way in which the fluidity can be altered. Changes in membrane fluidity may be an important way of regulating cell function. Klausner et al. (1980) suggest that changing membrane fluidity alters the topographical distribution of proteins in a lipid bilayer. In the present study we have shown that macrophages release fatty acids during activation, which might serve as regulatory chemicals in cell interaction.

The role of prostaglandins in the control of target cell function deserves special mention. Numerous reports described the control of various cells in the immune system by prostaglandins or other arachidonic acid metabolites; proistaglandins are involved in the control of lymphocyte function (Mihas et al. 1975; Smith et al. 1971; Goodwin et al. 1977; Goodwin et al. 1977), 
certain hydroxyeicosatrienoic acids are chemotactic for eosinophils and neutrophils (Goetzl et al. 1980; Meade and Mertin, 1978), and unsaturated fatty acids have been implicated in the control of various membrane functions in lymphocytes (Hoover et al. 1980; Corps et al. 1980). This phenomenon clearly needs to be examined further.

In summary, we have shown that macrophages when treated with zymosan, PMA, and LPS, release increased amounts of fatty acids into the media, as compared to controls. In addition, the type of stimulus used determines the selectivity of fatty acid release from cell lipids. The role of fatty acids released from macrophages in the control of target cell function needs to be investigated.

Acknowledgment: This work was supported by NIH grant \#1R23 AI 16147. Prostaglandin standards are generously provided by Dr. John Pike from the Upjohn Co., Kalamazoo, Michigan. M. M. Y. is a recipient of a grant from the Nisshin Seifun Foundation, Japan.

\section{References}

Bell, R. L., Kennerly, D. K., Stanford, N. and Majerus, P.W. (1979). Diglyceride lipase: A pathway for arachidonate release from human platelets. Proc. Natl. Acad. Sci. USA, 76, 3238-3241.

Bills, T. K. Smith, J. B. and Silver, M. J. (1977). Selective release of arachidonic acid from the phospholipids of human platelets in response to thrombin. J. Clin. Invest. 60, 1-6.

Bonney, R. J., Wightman, P.D., Davies, P., SADOWski, S. J., KueHl, Jr. F. A. and Humes, J. L. (1978). Regulation of prostaglandin synthesis and of the select release of lysosomal hydrolases by mouse peritoneal macrophages. Biochem. J. 176, 433-442.

Bonney, R. J., Naruns, P., Davies, P. and Humes, J. L. (1979). Antigen-antibody complexes stimulate the synthesis and release of prostaglandin by mouse peritoneal macrophages. Prostaglandins, 18, 605-616.
Corps, A. N., Pozzan, T., Hesketh, T.R. and Metcalfe, J.C. (1980). Cis-unsaturated fatty acids inhibit cap formation on lymphocytes by depleting cellular ATP. J. Biol. Chem. 255, 10566-10568.

Croop, J., Toyama, Y., Dlugosz, A. A. and Holtzer, H. (1980). Selective effects of phorbol 12myristate 13 -acetate on myofibrils and 10 nm. filaments. Proc. Natl. Acad. Sci. USA, 77, 5273-5277.

De Haas, G. H., Postema, N. M., Nieuwenhuizen, W. and Van Deenen, L. L.M. (1968). Purification and properties of phospholipase A from porcine pancreas. Biochem. Biophys. Acta. 159, 103-117.

Ferluga, J., Schorlemmer, H. U., Baptista, L.C. and Allison, A.C. (1978). Production of the complement cleavage product $\mathrm{C} 3 \mathrm{a}$ by activated macrophages and its tumorlytic effects. Clin. Exp. Immunol. 31, 512-517.

Goetzl, E. J., Derian, C. and Valone, F. H. (1980). The extracellular and intracellular roles of hydroxy-eicosatetraenoic acids in the modulation of polymorphonuclear leukocyte and macrophage function. J. of Reticuloendothelial Soc. 28, 105s-111s.

Goetzl, E. J., Woods, J. M. and Gorman, R. R. (1977). Stimulation of human eosinophil and neutrophil polymorphonuclear leukocyte chemotaxis by 12 -L-hydroxy-5, 8, 10, 14-eicosatetraenoic acid. J. Clin. Invest. 59, 179-183.

Goodwin, J.S., Bankhurst, A.D. and Messner, R. P. (1977). Suppression of Human T-cell mitogenesis by prostaglandins: Existence of a prostaglandin-producing suppressor cell. J. Exp. Med. 146, 1719-1734.

Goodwin, J.S., Messner, R.P., Bankhurst, A.D., Peak, G.T., Saiki, J.H. and Williams, R.C. (1977). Prostaglandin Producing Suppressor Cells in Hodgkins Disease. New Eng. J. Med. 297, 963-968.

Gordon, J.L., Maclntyre, D.E. and McMillan, R.M. (1977). Effect of divalent cations on lysosomal enzyme release from macrophages. Br. J. Pharmacol. 61, 452-453.

Hamberg, M. and Samuelsson, B. (1966). Prostaglandins in human seminal plasma: Prostaglandins and related factors. J. Biol. Chem. 241, 257-263.

Hatten, M.E., Scandella, C. J., Horwitz, A. F. and Burger, M. M. (1978). Similiarities in the membrane fluidity of 3T3 and SV 101-3T3 cells and its relation to concanavalin $\mathrm{A}$ and wheat 
germ agglutinin-induced agglutination. J. Biol. Chem. 253, 1972-1977.

Hauser, M. and Guyer, W. (1979). Clustering of fatty acids in phosholipid bilayers. Biochem. Biophys. Acta. 553, 359-364.

Hong, S. L. and Levine, L. (1976). Stimulation of prostaglandin synthesis by bradykinin and thrombin and their mechanisms of action on MC5-5 fibroblasts. J. Biol. Chem. 251, 58145816.

Hoover, R. L., Bhalla, D. K., Yanovich, S., Inbar, M. and Karnovsky, M. J. (1980). Effects of linoleic acid on capping, lectin mediated $\mathrm{mi}$ togenesis, surface antigen expression and fluorescent polarization in lymphocytes and BHK cells. J. Cell Physiology. 103, 399-406.

Hsueh, W., Isakson, P.C. and Needleman, P. (1977). Hormone selective lipase activation in the isolated rabbit heart. Prostaglandins, 13, 1073.

Hsueh, W., Kuhn, C. and Needleman, P. (1979). Relationship of prostaglandin secretion by rabbit alveolar macrophages to phagocytosis and lysosomal enzyme release. Biochem. J. 184, 345-354.

Hsueh, W., Desai, U., Gonzalez-Crussi, F., Lamb, R. and $\mathrm{CHU}, \mathrm{A}$. (1981). Evidence for the existence of two phospholipase pools for prostaglandin synthesis in macrophages. Nature, 290, 710-713.

Hubbard, W. C., Hough, A. J., Brash, A. R., Wat son, J. T. and OAtes, J. A. (1980). Metabolism of linoleic and arachidonic acids in $\mathrm{VX}_{2}$ carcinoma tissue: Identification of monohydroxy octadecadienoic acids and monohydroxy eicosatetraenoic acids. Prostaglandins, 20, 431447.

Humes, J. L., Davies, P., Bonny, R. J. and Kuehl, JR., F.A. (1978). Phorbol myristate acetate (PMA) stimulates the release of arachidonic acid and its cyclooxygenation products by macrophages. Fed. Proc. 17, 1318.

Humes, J. L., Bonny, R. J., Pelus, L., Dahlgran, M. E., Sadowski, S. J., Kuehl, JR. F. A. and Davies, P. (1977). Macrophages synthesize and release prostaglandins in response to inflammatory stimuli. Nature, 269, 149-151.

Klausner, R. D., Bhalla, D. K., Dragsten, P., Hoover, R. L. and Karnovsky, M. J. (1980). Model for capping derived from inhibition of surface receptor capping by free fatty acids. Proc. Natl. Acad. Sci. USA, 77, 437-441. Maeda, C. J. and Mertin, J. (1978). Fatty acids and immunity. Adv. Lipid. Res. 16, 127.

MAHLER, H. R. (1964). Biological oxidation of fatty acids. In K.S. Markley, Fatty Acids., 2nd edn., Part 3. New York; Interscience.

Mihas, A. A., Gibson, R.G. and Hirschowitz, B. I. (1975). Suppression of lymphocyte transformation by 16 (16) Diemethyl Prostaglandin $E$ and unsaturated fatty acids. Proc. Soc. Exp. Biol. Med. 149, 1026-1028.

ÖGmundspottir, H. and Weir, D. M. (1980). Mechanism of macrophage activation. Clin. Exp. Immunol. 40, 223-234.

Passwell, J.H., Dayer, J.M. and Merler, E. (1979). Increased prostaglandin production by human monocytes after membrane receptor activation. J. Immunol. 123, 115-120.

Passwell, J. H., Dayer, J. M., Gass, K. and Edelson, P. J. (1980). Regulation by Fc fragments of the secretion of collagenase, $\mathrm{PGE}_{2}$ and $1 \mathrm{y}$ sozyme by mouse peritoneal macrophages. J. Immunol. 125, 910-913.

Phaire-Washington, L., Silverstein, S. and Wang, E. (1980). Phorbol myristate acetate stimulates microtubule and $10 \mathrm{~nm}$ filament extension and lysosome redistribution in mouse macrophages. J. Cell. Biol. 86, 641-655.

Piper, P. and Vane, J. R. (1971). The release of prostaglandins from lung and other tissues. Ann. N. Y. Acad. Sci. 110, 363-385.

Schremmer, J. M., Blank, M. L. and Wykle, R. L. (1979). Bradykinin-Stimulated Release of $\mathrm{H}$ arachidonic acid from phospholipids of $\mathrm{HSDM}_{1}$ $\mathrm{C}_{1}$ cells: Comparison of diacyl phospholipids and plasmalogens as sources of prostaglandin precursors. Prostaglandins, 18, 491-505.

Scott, W. A., ZRike, J. M., Hamill, A.L., Kempe, J. and CoHn, Z. A. (1980). Regulation of arachidonic acid metabolities in macrophages. J. Exp. Med. 152, 324-335.

Smith, J. W., Steiner, A.L. and Parker, C.W. (1971). Human lymphocyte metabolism: Ef fects of cyclic and noncyclic nucleotides on stimulation by phytohemagglutinin. J. Clin. Invest. 50, 442-448.

VoGt, W. (1978). Role of phospholipase $\mathrm{A}_{2}$ in prostaglandin formation: In Advances in Prostaglandin and Thromboxane Research. ed. C. Galli et al., Vol. 3, P. 89. New York; Raven Press.

Wahl, L. M., Wahl, S. M., Mergenhagen, S. E. and Martin, G. (1974). Collagenase production by endotoxin activated macrophages. Proc. Natl. Acad. Sci. USA. 71, 3598-3601. 